\title{
Developing Age-Friendly Cities: an Evidence-Based Evaluation Tool
}

\author{
Stefanie Buckner ${ }^{1}$ - Daniel Pope ${ }^{2}$. \\ Calum Mattocks ${ }^{1}$ - Louise Lafortune ${ }^{1}$. \\ Mukesh Dherani $^{2} \cdot$ Nigel Bruce $^{2}$
}

Received: 27 March 2017 / Accepted: 15 September 2017 / Published online: 6 October 2017

(C) The Author(s) 2017. This article is an open access publication

\begin{abstract}
Recent years have seen a proliferation of initiatives aimed at enhancing the age-friendliness of urban settings. The World Health Organization's (WHO) global Age-Friendly Cities (AFC) programme has been central to these. Cities seeking to become more age-friendly need reliable ways of assessing their efforts. This article describes an evidence-based evaluation tool for age-friendly initiatives whose development was informed by fieldwork in Liverpool/UK. The tool complements existing assessment frameworks, including those provided by WHO, by paying particular attention to the structures and processes underlying age-friendly initiatives. It reflects the complexity of age-friendliness by reconciling a focus on breadth with detail and depth, and it allows for a highly accessible visual presentation of findings. Using selected examples from Liverpool, the article illustrates how the evaluation tool can
\end{abstract}

Stefanie Buckner

sb959@medschl.cam.ac.uk

Daniel Pope

Danpope@liverpool.ac.uk

Calum Mattocks

cm726@medschl.cam.ac.uk

Louise Lafortune

11394@medschl.cam.ac.uk

Mukesh Dherani

M.K.Dherani@liverpool.ac.uk

Nigel Bruce

ngb@liverpool.ac.uk

1 Cambridge Institute of Public Health|, University of Cambridge|, Forvie Site, Robinson Way,

Cambridge CB2 0SR, UK

2 Department of Public Health and Policy, University of Liverpool, L69 3GB, Liverpool, UK 
be applied to guide policy and practice with an age-friendly focus in different urban contexts. Pilot testing in further settings is underway to refine the tool as a practical method for evaluation and for supporting city-level decision making.

Keywords Age-Friendly City · Evaluation tool · Ageing · Urbanisation · Complex interventions

\section{Introduction}

Ageing and urbanisation have for some time been recognised as converging global trends, with increasing proportions of older people living in cities (United Nations Department of Economic and Social Affairs Population Division 2014, 2015). In line with these phenomena, the last two decades have seen a proliferation of initiatives aimed at enhancing the ability of cities and communities to better address the needs of an ageing population. There is thus a need for reliable ways of assessing such efforts. This article introduces an evidence-based evaluation tool for age-friendly initiatives that was developed on the basis of fieldwork in Liverpool/UK. The tool complements existing assessment frameworks, including those provided by the World Health Organization (WHO), by paying particular attention to the structures and processes underlying age-friendly initiatives. It seeks to capture the complexity of age-friendliness by reconciling a focus on breadth with detail and depth, and it allows for a highly accessible visual presentation of findings. Using selected examples from Liverpool, the article illustrates how the evaluation tool can be applied to guide policy and practice with an age-friendly focus in urban contexts.

\section{Context}

Efforts in recent years to make urban settings better places to grow old in have been characterised by their diversity. Examples at the national level include the AdvantAge Initiative in the USA (Visiting Nurse Service of New York n.d.), and Ireland's AgeFriendly Cities and Counties Programme (Age Friendly Ireland n.d.). Prominent examples at the city level are the Age-Friendly New York City initiative (The New York Academy of Medicine n.d.), as well as the Age-Friendly Manchester programme in the UK (Manchester City Council 2016). An overview of further age-friendly initiatives is presented in a review by Steels (2015). Beyond a concern with urban settings, emphasis has been placed on the age-friendliness of rural communities, as illustrated by the recent publication of a relevant guide in Canada (Gallagher et al. n.d.).

A leading role in the response to global population ageing and urbanisation has been played by WHO. Relevant efforts have included its Age-Friendly Cities (AFC) programme, which commenced in 2006. Detailed accounts of this initiative and its development have been provided by others (Beard and Montawi 2015; Buffel et al. 2014; Buffel et al. 2012; Phillipson 2015; Plouffe and Kalache 2010). Based on research in 33 cities across all continents, WHO developed Global age-friendly cities: a guide (2007b) and an accompanying Checklist of essential features of age-friendly cities (2007a). These are organised around eight interlinking topic areas or domains 
(see Fig. 1). The intention behind the guide and checklist was to provide cities with a tool to identify their strengths and areas for improvement, to plan change, and to monitor progress (WHO 2007b).

In 2010, in order to encourage cities to take action WHO launched the Global Network of Age-Friendly Cities (WHO 2016a), which has subsequently become the Global Network of Age-Friendly Cities and Communities (Beard and Montawi 2015). The Network provides a platform for the exchange of experiences and for mutual learning and support. Joining requires a commitment from prospective members to a process of continually assessing and improving their age-friendliness (WHO 2016a). At the time of writing, the Network consisted of 400 cities and communities and 11 affiliated programmes in 37 countries (WHO n.d.). The twelve UK members include Manchester as a pioneer in the field nationally, and Liverpool as the research site for the study reported in this article (WHO 2016b).

Urban settings that seek to become more age-friendly need a way of assessing their age-friendliness and of monitoring progress. This is no straightforward undertaking:

Age-friendliness of an urban environment is a complex, dynamic and multidimensional concept which is also highly context dependent. Furthermore, the knowledge and science about it is still in a developing stage-age-friendliness is a moving target. Thus, it does not easily lend itself to standardization of measurement. (WHO Centre for Health Development 2015, p.65)

Frameworks for assessing and enhancing the age-friendliness of urban settings have become available through WHO. An early relevant resource is WHO's guidance for AFCs (2007b). However, the latter has been described as "very high level with little

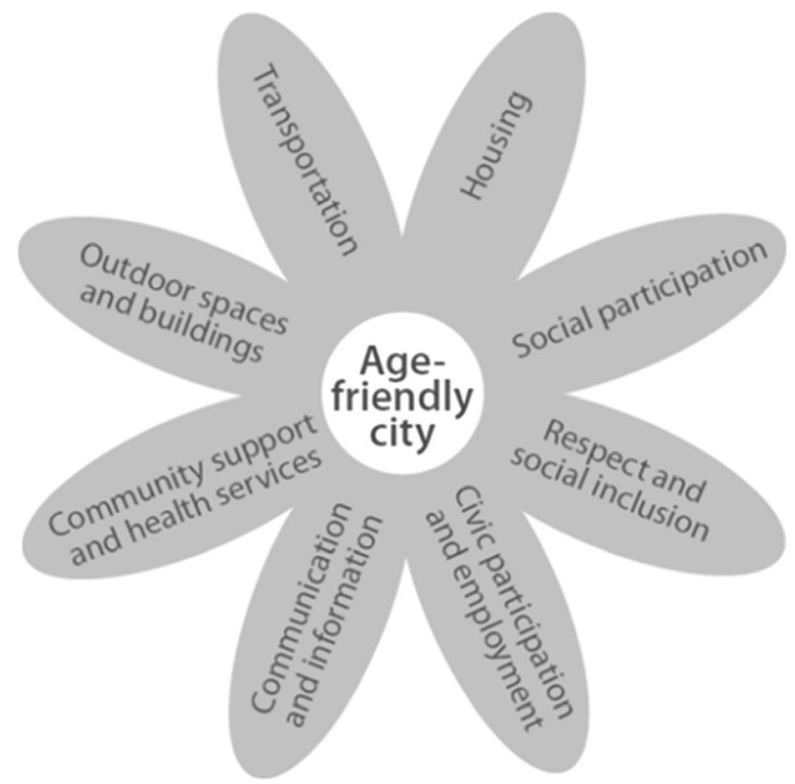

Fig. 1 WHO Age-Friendly City domains (WHO 2007b, p.9) 
tangible action items or recommendations" (Ruza et al. 2015, p.391), and as such "it did not gain much traction with urban planners and policymakers" [ibid.]. In its most recent effort to support cities in monitoring and enhancing their age-friendliness, WHO has published a set of core and supplementary AFC indicators (WHO Centre for Health Development 2015). Many of these are very specific (e.g. 'accessibility of public transportation vehicles'; 'engagement in volunteer activity') and indicate concrete areas for action.

In addition to WHO resources, other frameworks and guidance that can inform cities' assessments of their age-friendliness and relevant action are available. While a comprehensive review was beyond the scope of this study, a number of key features can be highlighted. It is not uncommon for approaches to be structured around the eight WHO AFC domains, although these are often adapted (Handler 2014; Phillipson et al. 2013a, b; Public Health Agency of Canada 2015; Ruza et al. 2015; Wong et al. 2015). There are frameworks that have been designed as generic evaluation instruments to be applied (and potentially adapted) to different settings (Handler 2014; Public Health Agency of Canada 2015; Ruza et al. 2015). At the same time, there are those that have been developed for specific contexts, and on which relevant efforts elsewhere can draw (Phillipson et al. 2013a, b; Wong et al. 2015). A broad distinction can be made between frameworks that are based on indicators of age-friendliness (Public Health Agency of Canada 2015; Ruza et al. 2015) and those where assessment does not involve the use of indicators. In examples of frameworks not based on indicators, mixed methods approaches to the evaluation of AFC initiatives are outlined (Phillipson et al. 2013a, b; Wong et al. 2015), and templates for evaluation offered (Handler 2014). In addition to assessment tools specific to AFCs, diverse frameworks exist that focus on related initiatives and issues in the field of ageing (European Innovation Partnership on Active and Healthy Ageing 2012; Feldman et al. 2003; Gallagher et al. nd; Kihl et al. 2005; United Nations Economic Commission for Europe 2015; Walsh and Harvey 2012). Both AFC-specific and related instruments are captured by a list of tools to evaluate the age-friendly process that has been compiled by the International Federation on Ageing, and in which examples from local and regional contexts in North America feature prominently (International Federation on Ageing n.d.).

A challenge for the evaluation of AFC initiatives is to identify an evidencebased approach cities can use that (i) can be applied in different contexts, (ii) reflects the complexity of the initiatives, (iii) draws on sound data to make assessments of potential or demonstrable effectiveness, and (iv) presents findings clearly to a mixed audience that can include decision makers and practitioners in cities, members of the public, and other stakeholders. This article introduces an evaluation tool that responds to these requirements.

\section{The Study}

The study that provided the context and evidence for developing the tool ran from late 2013 to early 2016. Its aim was to contribute to ensuring that efforts to enhance the agefriendliness of urban settings are evidence-based and evaluated. It was undertaken as part of the Ageing Well Programme of the National Institute for Health Research (NIHR) School for Public Health Research (SPHR) (2012-2017). 
We carried out fieldwork in Liverpool/UK, whose older population $(65+$ years $)$ is projected to increase by 46\% between 2012 and 2037 (Jones and Mason 2015). The city's Mayor signed a pledge in 2012 committing the city to the WHO AFC initiative. Liverpool is home to one of the SPHR partners, the University of Liverpool, which maintained links to key city agencies including the Public Health Department in the local authority. Foundations for collaboration on the development of an evaluation tool and its application in policy and practice were thus in place.

As we developed the evaluation tool on the basis of fieldwork in Liverpool, we simultaneously applied it to the city's work in relation to age-friendliness. The full findings from its application will be published separately. This article describes the rationale and development of the tool, and provides guiding principles for its application. Selected findings from Liverpool are used as examples to illustrate how the tool can function and guide policy and practice.

Ethical approval for the study was obtained from the relevant research ethics committees at the Universities of Liverpool and Cambridge.

\section{Methods}

\section{Development of AFC Evaluation Tool}

The development of the evaluation tool was carried out through an extensive, iterative process. It was informed by a scoping review of the literature on age-friendly initiatives, which included a particular focus on assessment and monitoring frameworks for age-friendliness. Combined with the findings from other data sources (see below), this allowed us to identify priorities for the evaluation of AFC initiatives that a tool would need to incorporate.

We undertook scoping conversations with professionals from a small number of UK cities and academic colleagues with expertise in ageing and AFCs at an early stage of the study. These provided insights into approaches to AFC initiatives in different urban contexts. They contributed to tool development by highlighting topic areas for exploration in subsequent data collection through interviews and focus groups (see below), such as governance arrangements for AFCs and ways of resourcing age-friendly initiatives.

Fieldwork in Liverpool commenced with a health needs assessment for older people that was based on existing data (Institute of Public Care 2013; Liverpool City Council 2013; Lucy et al. 2012; Office for National Statistics 2013a, b; Public Health England 2013; West Midlands Public Health Observatory 2013). It was apparent, initially from the city's Joint Strategic Needs Assessment (JSNA) (Liverpool City Council 2013) and subsequently from further analysis, that Liverpool had a very high mortality rate from falls among older people compared to other English cities, the North West, and England as a whole. We therefore selected falls and falls-related work as a case study of a local health priority. This gave the research a dual focus on both Liverpool's overall approach to age-friendliness, and falls-specific initiatives as a component of the latter. It meant a focus on two areas of work with related yet distinct priorities that differed in terms scope and stage of development (it emerged early on that falls-related work in the city had advanced further than the overall AFC initiative as a co-ordinated approach). This 
was expected to aid the development of an evaluation tool that could be adapted to different contexts and purposes.

We carried out 15 interviews with 17 key informants in policy and practice (see Fig. 2). The majority of these $(n=12)$ were individual interviews, with three interviews involving two key informants (one key informant was interviewed both individually and together with one other). The key informants were recruited on the basis of their roles in the city's AFC initiative and/or their falls specialism.

Qualitative data collection with older people involved twelve individual semistructured interviews and three focus groups with a total number of 18 older people (see Table 1). The older participants were residents and/or users of services and facilities in Liverpool who lived in the community or in sheltered/assisted living accommodation. Recruitment occurred through convenience sampling with the help of an older Liverpool resident who acted as Patient and Public Involvement (PPI) advisor to the study and a local care provider.

The topic guides for all interviews and focus groups with key informants and older people were informed by the literature and by the early scoping conversations with professionals and academic colleagues. They allowed for flexibility and thus balanced consistency and comparability with a potential for unexpected issues to emerge.

All interviews and focus group discussions were audio-recorded with the consent of the participants before being transcribed and anonymised. Coding and thematic analysis occurred separately for key informant interviews, interviews with older people and focus groups with older people. This process was led by one researcher (SB). The coding frameworks were checked by another team member (CM), as was coding accuracy. The latter involved checking a random selection of three coded excerpts for each node (in cases where fewer than three excerpts were coded, all of them were checked). Disagreements were resolved through discussion. In the subsequent thematic analysis three researchers (NB, CM, DP) provided ongoing feedback on the three evolving analysis documents, and the final documents were examined in detail by two team members (DP, CM). Disagreements were resolved within the team.

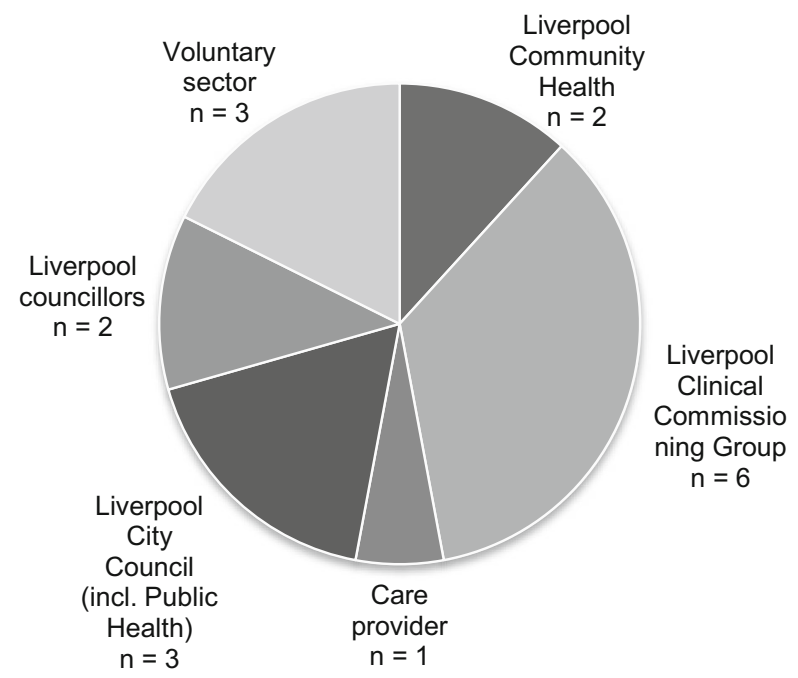

Fig. 2 Key informant sectors and agencies 
Table 1 Characteristics of older study participants

\begin{tabular}{|c|c|c|c|c|}
\hline & Interviewees & $\mathrm{n}$ & Focus group participants & $\mathrm{n}$ \\
\hline \multirow[t]{7}{*}{ Age } & $65-69$ & 4 & $65-69$ & 4 \\
\hline & $70-74$ & 1 & $70-74$ & 6 \\
\hline & $75-79$ & 2 & $75-79$ & 3 \\
\hline & $80-84$ & 3 & $80-84$ & 0 \\
\hline & $85-89$ & 1 & $85-89$ & 2 \\
\hline & $90+$ & 1 & $90+$ & 2 \\
\hline & & & Unknown & 1 \\
\hline \multirow[t]{2}{*}{ Sex } & $\mathrm{F}$ & 8 & $\mathrm{~F}$ & 14 \\
\hline & M & 4 & M & 4 \\
\hline \multirow[t]{2}{*}{ Ethnicity } & White British & 11 & White British & 18 \\
\hline & Black or Black British African & 1 & & \\
\hline \multirow[t]{6}{*}{ Housing } & Own property - owned outright & 8 & Own property - owned outright & 7 \\
\hline & Renting privately & 1 & Own property - mortgaged & 2 \\
\hline & Sheltered & 2 & Own property - no details & 5 \\
\hline & Other/unknown & 1 & Local authority & 2 \\
\hline & & & Social landlord & 1 \\
\hline & & & Assisted living & 1 \\
\hline \multirow[t]{6}{*}{ Falls(s) (previous year) } & None & 6 & None & 5 \\
\hline & 1 & 2 & 1 & 5 \\
\hline & $3+/$ many' & 3 & 2 & 1 \\
\hline & Close other(s) had fall(s) & 1 & Near fall & 5 \\
\hline & & & Close other(s) had fall(s) & 1 \\
\hline & & & Unknown & 1 \\
\hline
\end{tabular}

The resulting themes were a major component in the development of the evaluation tool. They were integrated with insights from the literature and the additional methods used (analysis of routinely collected falls data; umbrella review of falls prevention interventions - see below) in order to identify thematic areas for which an evaluation of age-friendly initiatives would need to seek evidence.

The study involved two additional methods whose contribution to the development of the evaluation tool was less direct, and which were primarily relevant to the application of the tool in Liverpool. Both were linked to the falls case study. They are included here as part of a comprehensive methodological account, while their findings will be reported separately.

The first was a systematic review of systematic reviews (umbrella review) to identify effective falls prevention interventions (Dherani et al. 2015). Its findings were used to consider the extent to which falls prevention interventions in Liverpool reflect the evidence base on effectiveness. The umbrella review contributed to the development of the tool in that it drew attention to the importance of considering cities' use of evidence to inform their efforts to become more age-friendly.

The second method was the analysis of routinely collected falls data (Hospital Episode Statistics/morbidity data; Public Health England/mortality data; Census/Index of Multiple 
Deprivation data). We aimed to arrive at a detailed understanding of falls in Liverpool, including the possible causes and locations, and falls-related inequalities. This analysis highlighted that it is important to examine cities' efforts to assess health needs as a basis for AFC interventions, as this enables an assessment of the extent to which interventions and priorities are informed by evidence of need. In particular, it drew attention to data availability and accessibility as factors that need to be considered.

\section{The Role of Logic Models}

Data collection was informed by a logic model for falls in Liverpool (see Fig. 5a). Logic models have been defined as "diagrams or flow charts that convey relationships between contextual factors, inputs, processes and outcomes" (Baxter et al. 2010, p.100). They are designed to evolve through revision as more information becomes available during the course of an intervention or evaluation (Leviton et al. 2010).

A logic model for falls began to evolve during the early stages of the fieldwork on the basis of the literature and emerging findings. As further insights became available, we refined it in an iterative process. The logic model in turn shaped the evaluation tool in that it informed data collection by visualising areas where more evidence was needed.

Development of a logic model describing a system as complex as Liverpool's overall AFC initiative initially appeared unlikely to provide a useful overview. Later in the research process, however, once we had a substantial body of findings, insights from the literature, and an evaluation tool whose development had reached an advanced stage, we felt that a concise depiction of key areas and processes was both feasible and useful (see Fig. 5b). Given its development at this later stage, the logic model for Liverpool's AFC initiative did not play the same part as the falls logic model in shaping the evaluation tool. What both logic models have in common is their status as key outputs from the study that other AFC initiatives can draw on in ways that are discussed further below.

\section{Outputs}

\section{An Evidence-Based Evaluation Tool}

Based on the literature and the emerging findings from the fieldwork we identified ten 'input areas' for which evidence is required to assess policy and practice initiatives designed to be age-friendly. These make up the evaluation tool (see Table 2). The broad scope of the tool, and the capacity to gain detailed context-specific insights, is consistent with the "complex, dynamic and multi-dimensional" and also "highly context dependent" nature of age-friendliness of urban environments that has been highlighted by WHO Centre for Health Development ( 2015, p.65).

We propose that in applying the tool, an evidence synthesis table is used to record key findings for the individual input areas (see Table 3 - with exemplary data for input area 5: Priorities based on needs assessment). Once the input area has been specified (first row), the data sources from which evidence relevant to this area is available are recorded (first column). Where appropriate, references or hyperlinks to the original source documents can be incorporated. Ultimately, the tool is designed to assess a city's performance in policy and practice (third column). This is preceded by appraisal of the 
Table 2 AFC evaluation tool

Input areas

1 Political support

2 Leadership and governance

3 Financial and human resources

4 Involvement of older people

5 Priorities based on needs assessment

6 Application of existing frameworks for assessing age-friendliness

7 Provision

8 Interventions rooted in evidence base

9 Co-ordination, collaboration and interlinkages

10 Monitoring and evaluation
Definitions

Backing (verbal and/or practical) from key political players locally - e.g. mayor, councillors, parties

Structures and roles for strategic overview \& management

Commitment of funding, material means, staff, volunteers, investment in staff and volunteers

Instrumental roles and contributions from older people. Includes available structures, nature of structures, nature of contributions, impact of contributions

Initiatives have been prioritised on the basis of a JSNA and/or other ways of assessing needs

Use by the city of existing guidance and assessment frameworks by WHO (e.g. 2007a; 2015) or others (e.g. Handler 2014) to inform its work on age-friendliness

Availability of relevant services and facilities, including consistency (e.g. geographical coverage) and continuity (availability and personnel), and consideration of issues around uptake

Scientific evidence base has been consulted and interventions have been based on the available evidence

Partnership working across sectors, co-ordination of relevant activities, and interlinkages between different areas of focus

Monitoring and evaluation of ongoing and completed work, including plans for monitoring and evaluation and allocation of resources. Nature of monitoring and evaluation.

Translation of findings into policy and practice

available evidence (second column) in order to ensure transparency about the quality of the data on which performance assessment is based.

Criteria for the appraisal of evidence depend on the methods and data sources used. The evaluation tool offers flexibility in this respect. Tool users select the methods and sources through which evidence will be obtained, thus ensuring relevance to the local context. This is likely to involve consideration of existing information, for example in the form of routinely collected statistical data. Additionally, users might opt to collect new evidence, subject to the availability of relevant expertise and resources. There are no restrictions on methods and data sources that are feasible and appropriate in a specific context, and it is worth noting here the potential of participatory methods as a way for older people to become involved in shaping urban settings. Based on the methodological choices made, evidence appraisal criteria need to be determined. There is no shortage of relevant scientific literature that tool users can draw on. Examples of literature relevant to the qualitative methods used in the Liverpool case study include the Critical Appraisal Skills Programme (CASP) (2013), Walsh and Downe (2006), Horsburgh (2003), Williamson (2009) and Popay et al. (1998). This is a complex field in which tool users in cities might find collaboration with research partners beneficial.

In the Liverpool study we appraised the available evidence for each input area by considering the amount of data, the degree of detail provided by the data, and the heterogeneity of the informants with respect to their professional positions (in the case 
Table 3 Evidence synthesis table for application of AFC evaluation tool (populated with exemplary data from Liverpool's AFC initiative)

AFC tool input area 5: Priorities based on needs assessment

$\begin{array}{ll}\text { Data sources Evidence appraisal } & \begin{array}{l}\text { Assessment of city performance in policy and } \\ \text { practice }\end{array}\end{array}$
practice

\begin{tabular}{|c|c|}
\hline $\begin{array}{l}\text { JSNA and } \\
\text { specific } \\
\text { Health Needs } \\
\text { Assessments } \\
\text { (HNAs) }\end{array}$ & 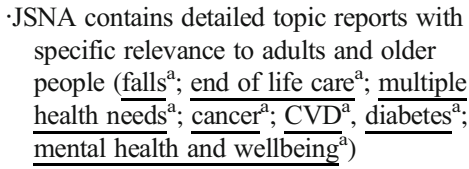 \\
\hline & $\begin{array}{l}\text {-Additional detailed HNAs relevant to } \\
\text { age-friendliness, incl. Older People's } \\
\text { HNA }^{\mathrm{a}} \text { and Dementia HNA }\end{array}$ \\
\hline
\end{tabular}

Key informant $\quad$ Topic addressed by many key informants interviews $^{\mathrm{a}} \quad$ well-placed to assess this and representing diverse agencies/positions, often in detail

Interviews with Topic addressed by one older interviewee older people $^{\mathrm{a}}$ to a very limited extent

Summary

Detailed data mainly from key Summary
-Detailed needs assessments have been, and continue to be, carried out

-Health and Wellbeing Board (HWB) agreed priorities for adults and older people in Sept 2013: cancer; long-term conditions; mental health; falls and fragility fractures referred to as "JSNA priorities" in Joint Health and Wellbeing Strategy (JHWS) They underpin JHWS, which has been developed by HWB in response to JSNA alongside on-going input from partners and local communities

-JSNA also informs other strategies, e.g. Healthy Liverpool Programme; Liverpool Dementia Strategy

-JSNA is on-going process designed to reflect changes in the local picture. Topic reports and HNAs are being updated and added on ongoing basis

-Appreciation of importance of assessing needs as a basis for interventions

-Efforts (previous and ongoing) to assess needs and identify priorities in general and older population

-Growing awareness, in context of cuts, of different opportunities and data sources. Changing thinking about ways of carrying out needs assessments (greater focus on existing resources, e.g. Public Health Team)

-Recognition of importance of seeking perspectives of older people, yet constrained by resource limitations

Questions remain about extent to which available evidence is consulted and acted upon

-Importance of assessing needs as a basis for identifying priorities

The data suggest an increasing

Summary informants well-placed to score 4 focus on assessing needs among older people as a basis for the identification of priorities. While resource limitations impose constraints on the availability of relevant data, there also 
Table 3 (continued)

AFC tool input area 5: Priorities based on needs assessment $\begin{array}{ll}\text { Data sources } \quad \text { Evidence appraisal } & \begin{array}{l}\text { Assessment of city performance in policy and } \\ \text { practice }\end{array}\end{array}$

older people well-placed to assess this issue.

Legend

$$
\begin{aligned}
& 1=\text { Very limited } \\
& 2=\text { Limited } \\
& 3=\text { Moderate } \\
& 4=\text { Strong } \\
& 5=\text { Very strong }
\end{aligned}
$$

Evidence appraisal scores

$0=$ insufficient data availability/quality

\begin{abstract}
appears to be a growing awareness of opportunities to draw on previously under-used resources. Questions do remain about the extent to which evidence of need is acted upon in formulating an AFC approach.
\end{abstract}

\section{Performance assessment scores}

- Not scored, due to insufficient data availability/quality

$0=$ Relevant efforts in city not identified

$1=$ Very weak

$2=$ Weak

$3=$ Moderate

$4=$ Strong

$5=$ Very strong

\footnotetext{
${ }^{\mathrm{a}}$ Links to the source documents are underlined
}

of the key informants) and their demographic characteristics (in the case of the older interviewees). We also considered the expertise of the informants in relation to the input area for which they provided information, and we identified further data collection methods that could have added to the evidence. This information was recorded in the evidence synthesis table (see Table 3; second column). In addition to this focus on individual input areas, we appraised all the evidence from data sources that supplied information for multiple input areas - the key informant interviews, the interviews with older people and the focus groups. Based on criteria suggested by CASP (2013), this involved assessing the appropriateness of method, recruitment, sample and data analysis for each data source. The findings contributed to evidence appraisal for all those input areas that drew on data from the respective source(s). They were recorded in a table that will be published separately. The approach used in the Liverpool study illustrates how evidence appraisal might be carried out. Application of the tool elsewhere is likely to involve at least some different data sources and, therefore, will require different appraisal criteria that need to be decided on by tool users.

On the basis of evidence appraisal in Liverpool, we carried out an assessment of city performance in policy and practice. Exemplary data with regards to Liverpool's overall AFC initiative are presented in Table 3 (third column). They illustrate how findings can be summarised and recorded, with references and hyperlinks to the source documents as appropriate.

We have included space for narrative summaries of both evidence appraisal and performance assessment into the evidence synthesis table. These accounts can be translated into summary scores. Evidence appraisal scores range from 0 to 5 . A score of 0 (zero) indicates that the minimum data requirements for an input area have not been 
met, and/or that the data quality is poor, with the implication that there can be no subsequent assessment of city performance for that input area. Scores for performance assessment also cover a scale from 0 to 5 . Where no assessment of city performance for an input area is possible due to insufficient data availability/quality, this is reflected in the absence of a score.

The scores can be presented in radar charts (see Fig. 3a and b). Visual representation of this kind provides an accessible overview that highlights strengths ('peaks') as well as limitations and areas requiring further attention ('dips'). In the study of Liverpool's AFC initiative, the evidence appraisal scores covered a relatively narrow range at the upper end of the scale (from 3 to 5) (see Fig. 3a). This meant that while there was some room for improvement, the available evidence allowed for a confident assessment of the city's AFC approach. The picture for city performance was more diverse, with scores ranging from 1 to 4 (see Fig. 3b).

We applied the evaluation tool to both Liverpool's overall AFC approach and the city's work specifically on falls. In both instances, all of the ten input areas were addressed. The adaptable nature of the tool allows users in other contexts to limit the
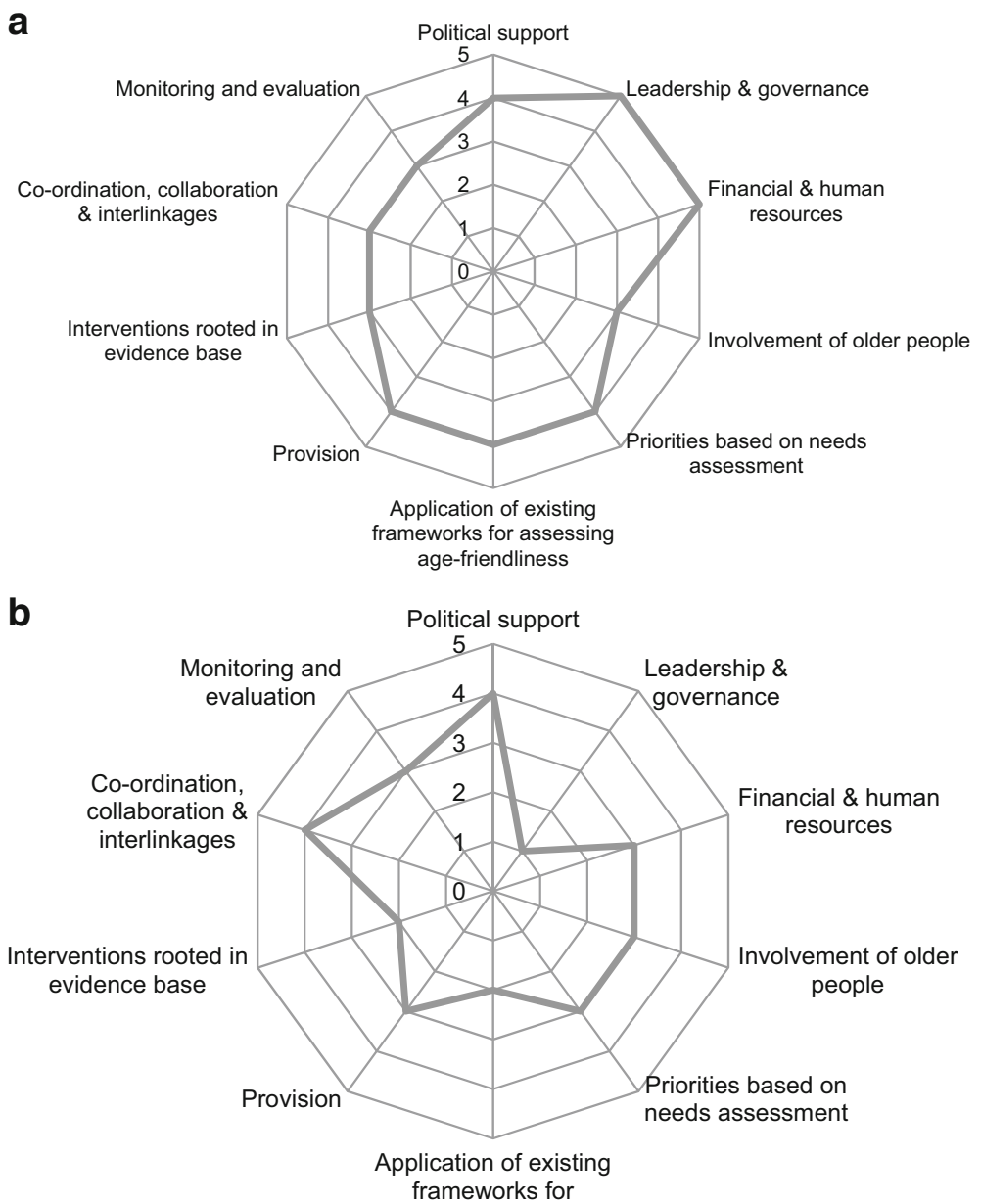

Fig. 3 a Liverpool's AFC initiative: Data availability and quality b Liverpool's AFC initiative: City performance in policy and practice 
focus to selected input areas where this is better suited to the nature of an intervention and/or the kind of assessment required, or where resource constraints dictate this.

The tool incorporates a focus on the extent to which existing frameworks for assessing age-friendliness have been used by a city to guide its work (input area 6). In addition, existing frameworks can be applied in combination with the tool. Put differently, a city assessment can benefit from an additional component where data that are available in relation to existing frameworks are recorded.

Where cities have worked with specific frameworks, these are an obvious choice for use together with the tool. In the case of Liverpool, the city had not apparently utilised existing AFC assessment frameworks in any formal or systematic way. We chose to apply the WHO set of core AFC indicators (WHO Centre for Health Development 2015; see Fig. 4) as part of our assessment of the city's performance on age-friendliness. Rather than collecting new evidence for this, we recorded the data we had available that seemed broadly relevant to specific indicators (the findings from this are published in a separate paper reporting on the findings in Liverpool).

The WHO indicators address issues important for AFCs that are often very specific. The evaluation tool, which incorporates a strong focus on the conditions for an AFC, is designed to capture evidence on a broader scale. While it can accommodate the kind of information relevant to the WHO indicators, this is subsumed within its (broader) input areas, particularly the areas of provision and involvement of older people. Applying the WHO indicators together with the tool can draw attention to important issues that are often very specific and would be less visible if the tool alone was relied upon.

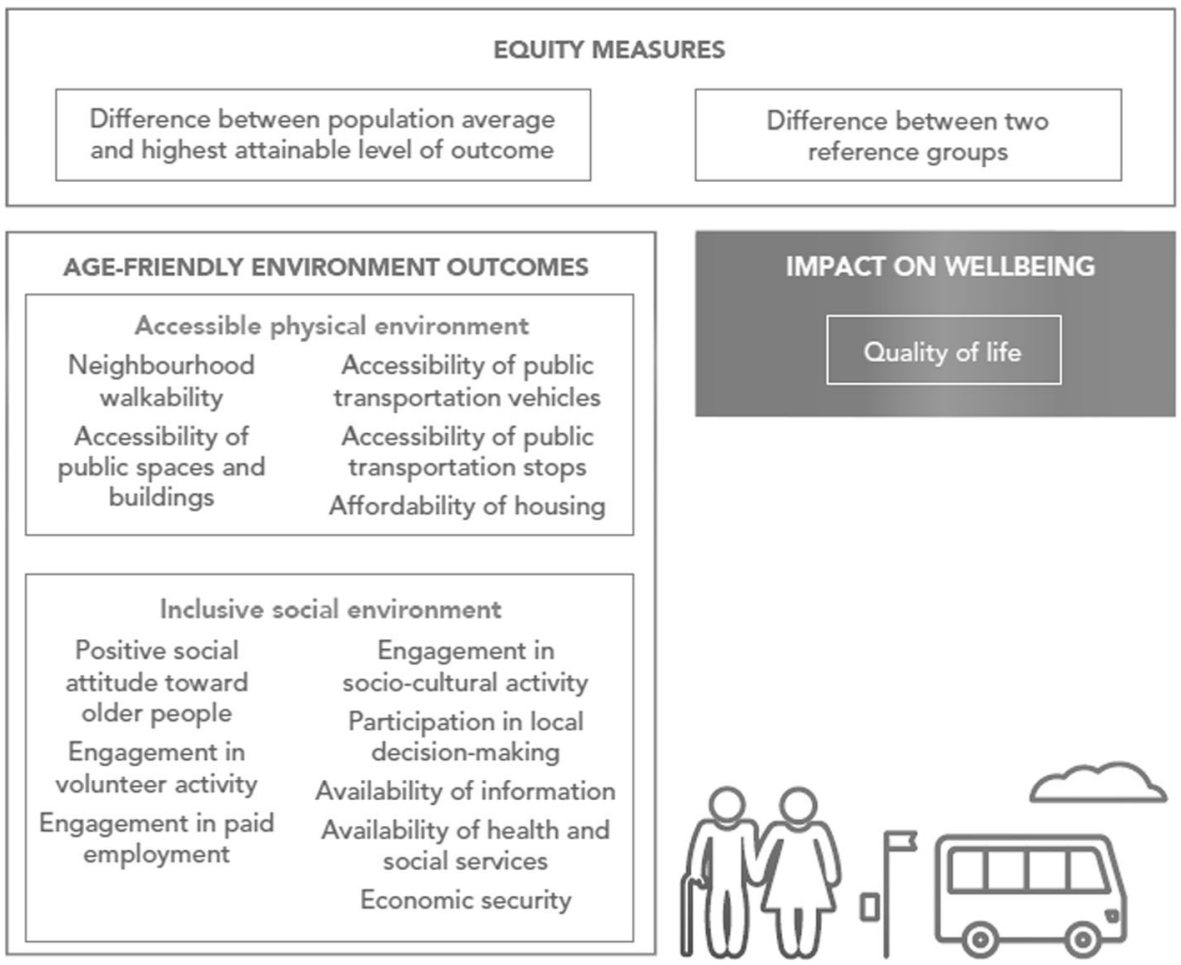

Fig. 4 WHO set of core AFC indicators (WHO Centre for Health Development 2015, p.27) 
a

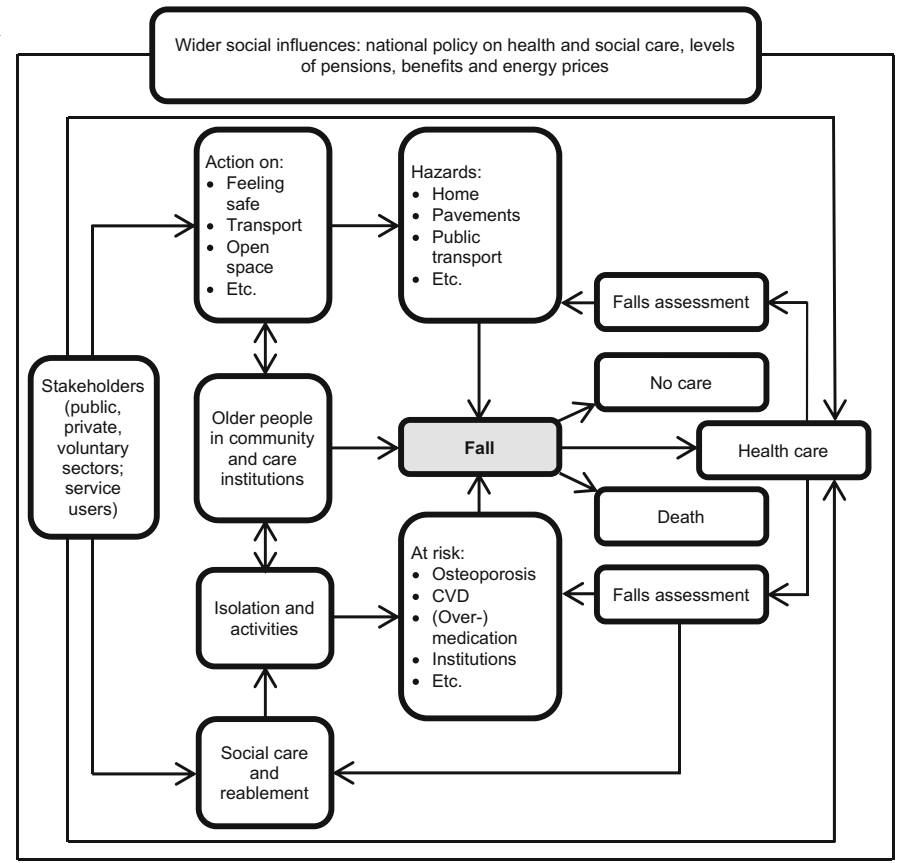

b
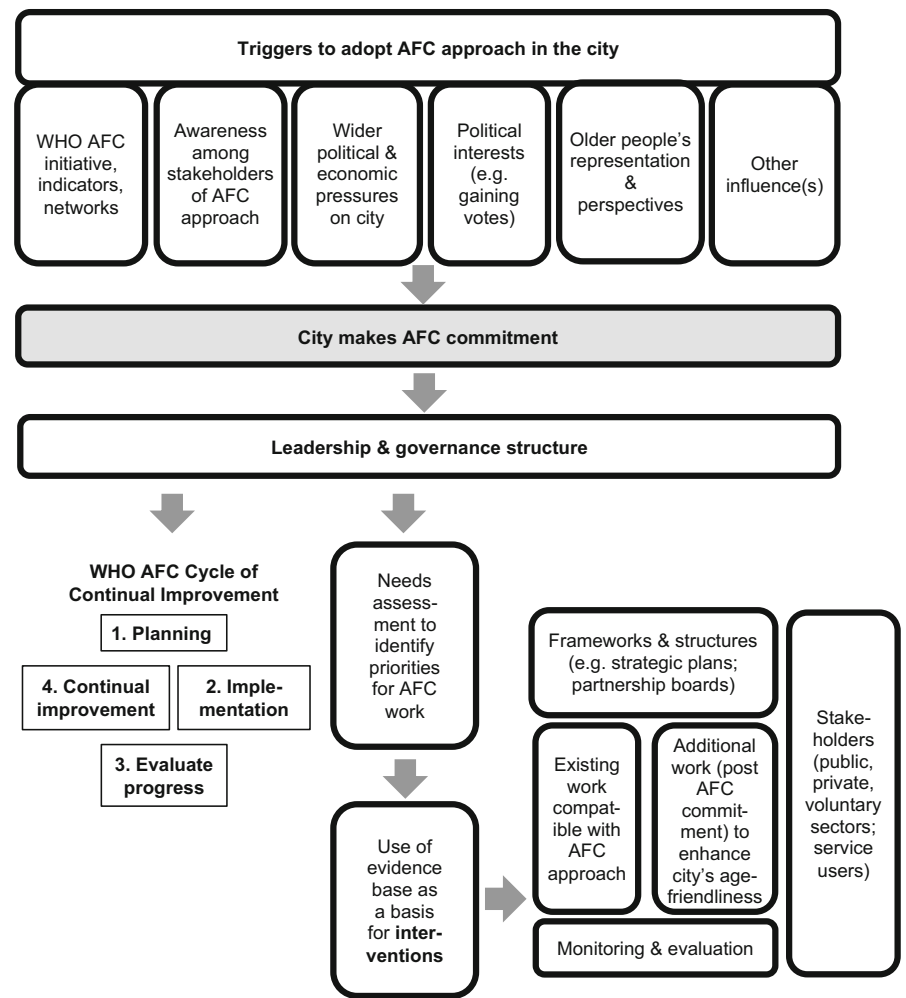

Fig. 5 a Logic model - Falls b Logic model - Overall AFC initiative 


\section{Logic Models}

In addition to an evaluation tool, the fieldwork in Liverpool resulted in logic models (see Fig. 5a and b). A critical function of both was supporting the communication of findings. Both proved valuable in feeding back the results of the assessments of city performance to local stakeholders. They visualised areas identified as requiring further work as well as areas of strength. At the same time, they facilitated an understanding of the processes and interlinkages through which these areas were anchored in the wider AFC system, and which would need to be considered in future work.

\section{Recommendations for Policy and Practice}

The findings from the assessment of Liverpool's overall focus on age-friendliness and its falls-related work highlight strengths in both areas. They thus draw attention to approaches and characteristics on which Liverpool can build, and from which other cities can learn. At the same time, they identify areas that require further attention. Challenges and gaps that became visible have formed the basis for researcher recommendations across the input areas of the tool that are rooted in the strengths in the city's work (published separately). In other contexts in which the approach described is applied, the strengths and gaps identified can inform a city's priorities for action.

\section{Discussion}

This study documents the development of an evidence-based evaluation tool that complements existing resources designed to assess age-friendly initiatives. The tool reflects the complexity and multi-dimensionality of age-friendliness highlighted by WHO Centre for Health Development (2015) through an approach that captures breadth, detail and depth. It can be useful to city leaders, public health practitioners and other stakeholders seeking to implement and assess initiatives designed to be age-friendly.

The development of the evaluation tool involved different methods and included an extensive review of the literature on AFCs. The fact that the latter is anchored in data from a single research site was determined by the available resources and might be viewed as a constraint. However, it facilitated the integration of a focus on detail and depth into the tool as the basis of a thorough assessment that relies on sound evidence. The evolving tool was presented to local stakeholders, practitioners, policy makers and academic colleagues from other cities and countries, and to WHO. It was refined on the basis of the feedback received from these experts and potential users. Its application in Liverpool has yielded detailed findings, which has indicated its suitability to assessing age-friendliness as a complex and context-dependent phenomenon. At present the tool is being pilot tested in other UK cities.

In line with the "highly context dependent" nature of age-friendliness in urban environments (WHO Centre for Health Development 2015, p.65), assessment of agefriendliness requires a flexible approach that is sensitive to local conditions. The importance of adaptability is acknowledged in existing frameworks (Handler 2014; Phillipson et al. 2013b; Public Health Agency of Canada 2015). Adaptability is a defining feature of the current tool. The tool has been developed on the basis of research into both Liverpool's overall AFC initiative and the city's work in relation to 
falls as a specific component within its wider age-friendly approach, and it has been applied to both contexts. This dual focus has supported the design of a tool that can be adapted to different contexts where age-friendly initiatives differ in terms of scope, priorities and stage of development. As well as allowing tool users to be selective with regards to the input areas on which to focus, the tool allows them to make locally appropriate choices on data requirements and data collection methods.

As noted earlier, it is not uncommon for existing approaches to evaluating agefriendliness to be structured around WHO's eight domains of AFCs (see Fig. 1). The domains lend themselves particularly well to a focus on provision of services and on involvement of older people in a city's AFC work. The current evaluation tool can be applied in combination with frameworks that are organised around these eight domains. At the same time, its input areas cut across the WHO-defined domains. They focus on structures and processes that create the conditions for an AFC. In addition, emphasis is placed on cities' use of the evidence base for work with an age-friendly focus (in the form of local needs assessments, evidence in the literature on the effectiveness of interventions, and also monitoring and evaluation). By recognising WHO's eight domains and complementing the perspective they offer, it can be claimed that the tool is well suited to capturing the complexity of the conditions relevant to a city's age-friendliness.

There has been a recent focus by WHO on the development of indicators of agefriendliness to support cities with assessment and monitoring (WHO Centre for Health Development 2015). This was echoed by the Public Health Agency of Canada, which published indicators specifically for the Canadian context (2015). The WHO guide states that it is aimed at developing a small set of indicators that can provide "a snapshot of the age-friendliness of a city" (WHO Centre for Health Development 2015, p.16), or "a fairly comprehensive picture without unnecessary detail" [ibid., p.15]. The focus on a limited number of indicators can be an appropriate way of managing resource constraints while obtaining an overview and ensuring comparability over time (i.e. monitoring progress). However, indicators are often fairly specific, as is illustrated by examples such as 'neighbourhood walkability' and 'accessibility of public transportation stops' (WHO Centre for Health Development 2015), and their numbers are limited ( $n=16$ ( +7 supplementary indicators) in the case of WHO; $n=43$ in the case of Public Health Agency of Canada). This might be seen as resulting in too narrow a picture. The current evaluation tool adopts a broad perspective where evidence is collected for ten relatively open input areas. It is based on the premise that for the assessment of age-friendliness as a complex, dynamic and multi-dimensional issue (WHO Centre for Health Development 2015), such breadth is critical. At the same time, the tool can accommodate a more focused approach on selected input areas, in line with resource availability and the requirements of the assessment exercise.

The current tool supports the collection and recording of detailed evidence. Access is provided to the original data sources and analysis documents through references and hyperlinks (see Table 3). At the opposite end of the spectrum, a key feature of the tool is the translation of detailed findings into summary scores. These are presented in a visual format (Fig. 3a and b) that provides an accessible overview.

As illustrated above, the tool can be used together with assessment frameworks that focus on specific aspects of AFCs. In feedback on the tool and its use together with the WHO indicators (WHO Centre for Health Development 2015), WHO recognises the 
complementarity of the two instruments and their potential, when used jointly, to support planning, implementation and target setting in the creation of age-friendly environments (personal communication S Buckner with P Rosenberg 2016).

The tool has been developed in conjunction with logic models. Logic models are widely used in both the implementation and assessment of AFC initiatives (e.g. Jackisch et al. 2015; Nova Scotia Centre on Aging 2012; Public Health Agency of Canada 2015; WHO Centre for Health Development 2015). They can help with identifying areas for attention in an assessment of age-friendliness (WHO Centre for Health Development 2015). The logic models developed in the current study are adaptable to different geographical and thematic contexts. By drawing attention to key areas in an AFC system, they can guide data collection for monitoring and evaluation, and they can support the identification of indicators for monitoring a city's progress towards greater age-friendliness. They can help to communicate the findings from a city assessment and inform subsequent action by visualising areas and processes that function well and those that require further attention.

It is recommended that application of the tool occurs through a steering group that consists of representatives from diverse city sectors as well as older people. In the Liverpool study, the process was researcher-driven as it occurred in parallel to the tool being developed, with input from city stakeholders at various stages. Where the process will be driven by cities and their evaluation needs, collaboration with individuals with expertise in conducting complex evaluations seems critical. The latter can provide advice and guidance. Importantly, collaborators not involved in policy and practice in a city are well-placed to act as facilitators in the assessment of local initiatives as a process that can expose tensions among stakeholders.

We acknowledge some limitations to this study. The tool has been informed to a substantial extent by interview and focus group data from Liverpool. Despite sustained efforts in the recruitment of participants, some gaps in the samples remained. The key informant sample lacked representation from the business sector. However, the diverse areas of expertise of the participants meant that information that a business perspective might have contributed (e.g. around multi-agency partnership working) was not necessarily missing. With regards to the older interviewees and focus group participants, greater heterogeneity of the samples would have been desirable. Both male and non-White British participants were under-represented.

Feedback from WHO on the tool highlighted the importance of an equity dimension in relation to the input areas. An equity perspective was captured in aspects of the work, including a focus on the geographical distribution of age-friendly services in Liverpool, and analysis of falls data for the city by IMD (Index of Multiple Deprivation) quintile (reported elsewhere). Examples of how such a perspective could be extended include a focus on whether specific neighbourhoods or areas of work receive more resources than others, or whether older adults from across the socio-economic spectrum are involved in AFC work (personal communication S Buckner with P Rosenberg 2016). Rather than a separate input area, an equity perspective is a cross-cutting aspect of the tool that is integral to the different input areas and, subject to data availability, should form part of an assessment. Here it is worth noting the potential of spatial mapping for visualising inequality data, which has been demonstrated in the evaluation of an AFC initiative in Manchester (Phillipson et al. 2013a). There is a case for exploring the use of this approach within the framework of the evaluation tool. 
The study had been designed as a collaborative project with consistent stakeholder input. PPI was integral to the research. It occurred through the contributions of an older Liverpool resident who acted as a PPI advisor, and also through feedback from different PPI fora. At the same time, the extent of collaboration envisaged with stakeholders in policy and practice did not fully materialise. Input from city representatives into the study design and the research process was limited. However, once a draft version of the tool had become available stakeholder engagement through workshops and discussions intensified. There has been increased recent interest in assessing age-friendliness in Liverpool, and city stakeholders are considering the findings and recommendations from the study as a basis for action.

\section{Conclusion}

Increasing interest in recent years in the age-friendliness of cities and communities has been accompanied by a growing number of frameworks for assessment and monitoring. This article has presented an evidence-based evaluation tool that makes an innovative contribution to the field. The tool seeks to capture the complexity of age-friendliness. At its core is a focus on the structures and processes underlying age-friendly initiatives. In addition to remaining adaptable, it offers a highly accessible way of presenting findings.

An issue discussed with stakeholders was the potential relevance of the AFC tool to other city-wide strategies (e.g. families, health promotion, housing, etc.). As well as research into its adaptability to non-AFC initiatives, this suggests exploring the potential of the tool to act as an integrating framework for different city strategies that include an age-friendly agenda. This might focus on adapting the ten input areas so that they can act as a generic guide and assessment framework for and across diverse strategies.

Urban settings and the lives of older people within them are shaped both by local policies and by the wider (national and global) contexts in which they are situated. The tool presented here has been designed to capture influences at different levels (including for example government cuts to local authority budgets and, thus, the need for city councils to revise the extent and nature of service delivery). It is the role of cities with an age-friendly agenda to create environments where higher-level influences interact with local-level policies and action in such a way as to foster active ageing and living as well as possible in older age. The tool presented here provides cities with an evidence-based means to support that work.

Acknowledgements We would like to thank Mrs. Barbara Ackerley for her contributions as Patient and Public Involvement (PPI) representative throughout the study, Local Solutions in Liverpool for their help with participant recruitment, the participants of various PPI fora for their advice on the direction of the research, and stakeholders from Liverpool and beyond for their initial guidance and their feedback on the emerging tool. We are particularly grateful to the study participants for their time and their contributions.

Author Contributions NB conceived of the overall study and oversaw it, and together with SB and LL drafted the initial proposal. NB, SB and MD reviewed the AFC literature and collected the qualitative data. Analysis of the qualitative data was led by SB, with input from DP, CM and NB. The routine falls data were obtained and analysed by MD, with input from NB. The umbrella review on falls prevention interventions was carried out by DP, MD and CM, with input from NB and SB. LL provided ongoing advice on different 
components of the study and on its strategic direction as part of a wider research programme (SPRH Ageing Well Programme). The manuscript was drafted by SB, with input from NB, CM, DP and LL. All authors read and approved the final manuscript.

Funding The study was funded by the National Institute for Health Research (NIHR) School for Public Health Research (SPHR) in the UK as part of the Ageing Well Programme. Funders had no direct involvement in the design, conduct or reporting of the research. The views expressed are those of the authors and not necessarily those of the NHS, the NIHR or the Department of Health.

\section{Compliance with Ethical Standards}

Conflict of Interests The authors declare that they have no conflict of interest.

Informed Consent All interview and focus group participants signed participant consent forms.

Ethics Approval Ethics approval for the study was granted by the Institute of Psychology Health and Society (IPHS) Research Ethics Committee at the University of Liverpool (Ref. IPHS-1314-338), and the Cambridge School of the Humanities and Social Sciences (CSHSS) Ethics Committee.

Permissions Two figures (Fig. 1 and Fig. 4) were published by WHO. Their use in this context complies with WHO's publication policy.

Open Access This article is distributed under the terms of the Creative Commons Attribution 4.0 International License (http://creativecommons.org/licenses/by/4.0/), which permits unrestricted use, distribution, and reproduction in any medium, provided you give appropriate credit to the original author(s) and the source, provide a link to the Creative Commons license, and indicate if changes were made.

\section{References}

Age Friendly Ireland (n.d.). Age Friendly Ireland. http://agefriendlyireland.ie/cities-and-counties-programme/. Accessed 26 Apr 2016.

Baxter, S., Killoran, A., Kelly, M. P., \& Goyder, E. (2010). Synthesizing diverse evidence: The use of primary qualitative data analysis methods and logic models in public health reviews. Public Health, 124(2), 99-106.

Beard, J. R., \& Montawi, B. (2015). Age and the environment: The global movement towards age-friendly cities and communities. Journal of Social Work Practice, 29(1), 5-11.

Buffel, T., Phillipson, C., \& Scharf, T. (2012). Ageing in urban environments: Developing 'age-friendly' cities. Critical Social Policy, 32(4), 597-617.

Buffel, T., McGarry, P., Phillipson, C., De Donder, L., Dury, S., De Witte, N., Smetcoren, A.-S., \& Verte, D. (2014). Developing age-friendly cities: Case studies from Brussels and Manchester and implications for policy and practice. Journal of Aging \& Social Policy, 26(1-2), 52-72.

Critical Appraisal Skills Programme (CASP). (2013). 10 questions to help you make sense of qualitative research. http://www.biomedcentral.com/content/supplementary/2046-4053-3-139-S8.pdf. Accessed 17 Mar 2016.

Dherani, M., Buckner, S., Pope, D., Lafortune, L., \& Bruce, N. (2015). Preventing falls and associated mortality in older people: An umbrella review of systematic reviews. PROSPERO International Prospective Register of Systematic Reviews. http://www.crd.york.ac.uk/PROSPERO/DisplayPDF. php?ID=CRD42015010571. Accessed 05 Aug 2016.

European Innovation Partnership on Active and Healthy Ageing (2012). Action plan on 'innovation for agefriendly buildings, cities \& environments'. Conference of Interested Partners, Brussels. http://www.ifa-fiv. org/wp-content/uploads/2015/03/12-European-Innovation-Partnership-on-Active-and-Healthy-Ageing$\%$ E2\%80\%93-Action-Plan-on-\%E2\%80\%98Innovation-for-Age-Friendly-Buildings-Cities-andEnvironments\%E2\%80\%99.pdf. Accessed 22 July 2016.

Feldman, P. H., Oberlink, M. R., Simantov, E., \& Gursen, M. D. (2003). The AdvantAge Initiative developing community indicators to promote the health and well-being of older people. Family \& Community Health, 26(4), 268-274. 
Gallagher, E., Menec, V., \& Keefe, J. (n.d.). Age-friendly rural and remote communities: A guide. Public Health Agency of Canada.

Handler, S. (2014). A research \& evaluation framework for age-friendly cities. UK Urban Ageing Consortium.

Horsburgh, D. (2003). Evaluation of qualitative research. Journal of Clinical Nursing, 12(2), 307-312.

Institute of Public Care (2013). Projecting Older People Population Information System (POPPI). http://www. poppi.org.uk/. Accessed 04 Nov 2013.

International Federation on Ageing (n.d.). Age-friendly resource manual 2014/15. International Federation on Ageing.

Jackisch, J., Zamaro, G., Green, G., \& Huber, M. (2015). Is a healthy city also an age-friendly city? Health Promotion International, 30(suppl 1), i108-i117.

Jones, R., \& Mason, R. (2015). Liverpool's Joint Strategic Needs Assessment older people health needs assessment. Liverpool: Liverpool City Council.

Kihl, M., Brennan, D., Gabhawala, N., List, J., \& Mittal, P. (2005). Livable Communities: An evaluation guide. Washington: AARP Public Policy Institute.

Leviton, L. C., Kettel Khan, L., Rog, D., \& Dawkins, N. (2010). Evaluability assessment to improve public health policies, programs, and practices. Annual Review of Public Health, 31, 213-233.

Liverpool City Council (2013). Joint Strategic Needs Assessment. http://liverpool.gov.uk/council/strategiesplans-and-policies/adult-services-and-health/joint-strategic-needs-assessment/. Accessed 15 Nov 2013.

Lucy, J., Cornes, A., Cox, M., Cummings, S., Fearnehough, B., James, A., Jones, R., Kelly, S., Keville, J., Knott, S., Lloyd, K., Mercer, T., \& Wilkinson, E. (2012). Joint Strategic Needs Assessment (JSNA) 2012. Liverpool: Liverpool Council and Liverpool Primary Care Trust.

Manchester City Council. (2016). Our age-friendly work. http://www.manchester.gov.uk/info/200091/older people/7116/our_age-friendly_work. Accessed 26 Apr 2016.

Nova Scotia Centre on Aging. (2012). Age-friendly communities in Canada: Community implementation guide. Public Health Agency of Canada.

Office for National Statistics (2013a). Neighbourhood statistics. Area: Liverpool (local authority). http://www. neighbourhood.statistics.gov.uk/dissemination/LeadAreaSearch.do?a=5\&c=liverpool\&d=13\&r=1 $\& \mathrm{o}=362 \& \mathrm{i}=1001 \& \mathrm{~m}=0 \& \mathrm{~s}=1383123956905 \& \mathrm{enc}=1 \&$ areaSearchText=liverpool\&areaSearchType $=13$ \&extendedList=false $\&$ searchAreas $=$. Accessed 28 Oct 2013.

Office for National Statistics (2013b). Nomis official labour market statistics: Census 2011. http://www. nomisweb.co.uk/. Accessed 30 Oct 2013.

Phillipson, C. (2015). Developing age-friendly urban communities: Critical issues for public policy. Public Policy \& Aging Report, 25(1), 4-8.

Phillipson, C., White, S., Aftab, F., \& Hammond, M. (2013a). Old Moat: Age-friendly neighbourhood report. Manchester: Southway Housing Trust.

Phillipson, C., White, S., Aftab, F., \& Hammond, M. (2013b). Old Moat: Age-friendly research and evaluation toolkit. Manchester: Southway Housing Trust.

Plouffe, L., \& Kalache, A. (2010). Towards global age-friendly cities: Determining urban features that promote active aging. Journal of Urban Health, 87(5), 733.

Popay, J., Rogers, A., \& Williams, G. (1998). Rationale and standards for the systematic review of qualitative literature in health services research. Qualitative Health Research, 8(3), 341-351.

Public Health Agency of Canada. (2015). Age-friendly communities evaluation guide using indicators to measure progress. Ottawa: Public Health Agency of Canada.

Public Health England. (2013). Liverpool health profile 2013. Public Health England.

Ruza, J., Kim, J. I., Leung, I., Kam, C., \& Ng, S. Y. M. (2015). Sustainable, age-friendly cities: An evaluation framework and case study application on Palo Alto, California. Sustainable Cities and Society, 14, 390-396.

Steels, S. (2015). Key characteristics of age-friendly cities and communities: A review. Cities, 47, 45-52.

The New York Academy of Medicine (n.d.). Age-friendly New York City. http://www.agefriendlynyc. org/about-us.html. Accessed 26 Apr 2016.

United Nations Department of Economic and Social Affairs Population Division (2014). Urban and rural population by age and sex, 1980-2015 (version 3, August 2014). http://www.un. org/en/development/desa/population/publications/dataset/urban/urbanAndRuralPopulationByAgeAndSex. shtml. Accessed 20 Jul 2016.

United Nations Department of Economic and Social Affairs Population Division. (2015). World population ageing 2015. New York: United Nations.

United Nations Economic Commission for Europe (2015). Active Ageing Index. http://www1.unece. org/stat/platform/display/AAI/Active+Ageing+Index+Home. Accessed 22 July 2016.

Visiting Nurse Service of New York (n.d.). The AdvantAge Initiative: Improving communities for an aging society. http://www.vnsny.org/advantage/. Accessed 10 Dec 2014.

Walsh, D., \& Downe, S. (2006). Appraising the quality of qualitative research. Midwifery, 22(2), 108-119. 
Walsh, K., \& Harvey, B. (2012). Review of age friendly counties Programme.

West Midlands Public Health Observatory. (2013). The Older People's Health and Wellbeing Atlas. http://www.wmpho.org.uk/olderpeopleatlas/Atlas/atlas.html. Accessed 28 Oct 2013.

Williamson, K. M. (2009). Evidence-based practice: Critical appraisal of qualitative evidence. Journal of the American Psychiatric Nurses Association, 15(3), 202-207.

Wong, M., Chau, P. H., Cheung, F., Phillips, D. R., \& Woo, J. (2015). Comparing the age-friendliness of different neighbourhoods using district surveys: An example from Hong Kong. PloS One, 10(7), e0131526.

World Health Organization. (2007a). Checklist of essential features of age-friendly cities. World Health Organization.

World Health Organization. (2007b). Global age-friendly cities: A guide. Geneva: World Health Organization.

World Health Organization. (2016a). WHO Global Network of Age-Friendly Cities and Communities. http://www.who.int/life-course/partners/agefriendlyworld/en/. Accessed 16 Mar 2016.

World Health Organization. (2016b). WHO Global Network of Age-Friendly Cities and Communities. https://extranet.who.int/sree/Reports?op=vs\&path=/WHO_HQ_Reports/G21/ PROD/EXT/GNAFCC\%202. Accessed 29 Apr 2016.

World Health Organization (n.d.). Age-friendly world. https://extranet.who.int/agefriendlyworld/. Accessed 19 May 2017.

World Health Organization Centre for Health Development. (2015). Measuring the age-friendliness of cities: A guide to using core indicators. Kobe: World Health Organization Centre for Health Development. 